\title{
CHEMOSPHERE
}

\section{Determination of bromate and chlorinated haloacetic acids in bottled drinking water with chromatographic methods}

\author{
Yongjian Liu, Shifen Mou* \\ Research Center for Eco-Environmental Sciences, Chinese Academy of Sciences, P.O. Box 2871, Beijing 100085, China
}

Received 7 January 2003; received in revised form 29 October 2003; accepted 28 December 2003

\begin{abstract}
Disinfection by-products of interest such as bromate, chlorate and chlorinated haloacetic acids in 10 representative brands of bottled drinking water were investigated with ion chromatography. With the developed method, the detection limits of the disinfection by-products were in sub- $\mu \mathrm{g} \mathrm{l}^{-1}$ level. It was observed that bromate, chlorate and dichloroacetic acid could be detected in some water samples. In the bottled natural water, the concentrations for the three compounds were $0.1,0.9$ and $0.6 \mu \mathrm{g}^{-1}$, respectively. The total concentration of disinfection by-products in the natural water sample was the highest among all the bottled drinking waters. The concentrations for the sum of disinfection by-products in the four types of bottled drinking water investigated were natural water $>$ mineral water $>$ spring water $>$ purified water. The generation of disinfection by-products was much influenced by the original components and process procedure of the source water. The concentrations of bromate and chlorate in the bottled water samples hardly degraded with the increasing storage time. For dichloroacetic acid, with the prolonging of storage time, the concentration was much decreased.
\end{abstract}

(C) 2004 Elsevier Ltd. All rights reserved.

Keywords: Bottled drinking water; Disinfection by-products; Ion chromatography; Bromate determination and haloacetic acid determination

\section{Introduction}

Bottled drinking water has become a healthier choice than tap water for many people because they believe that bottled drinking water contains fewer contaminants, or dislike the taste of chlorinated tap water. Therefore, the annual consumption of bottled drinking water in the world is substantial (Pip, 2000). For health concern, there is increasing attention on the quality of bottled drinking water (Allen and Darby, 1994; Calabrase, 1997; Misund et al., 1999; Ikem et al., 2002). However, most of the research concentrated on the element, inorganic

\footnotetext{
${ }^{*}$ Corresponding author. Tel.: +86-10-6284-9182; fax: +8610-6284-9239.

E-mail address: shifenm@mail.rcees.ac.cn (S. Mou).
}

anions, etc. in the water. Few data were reported on the concentration of disinfection by-products (DBPs) in it (Dionex, 2000).

It is well known that much of bottled drinking water passes through treatment processes such as filtration, deionization, reverse osmosis, and ozonation to ensure its quality. However, during the disinfection procedure, because of the existence of some organic materials or halides which is naturally occurring in source water and may not be entirely removed during the treatment processes. Ozone can react with the compounds and lead to the formation of DBPs such as bromate and haloacetic acids (HAAs) (Grguric et al., 1994; von Gunten and Oliveras, 1998; Dojlido et al., 1999).

Bromate has been judged by both the World Health Organization (WHO) and the US Environmental Protection Agency (USEPA) as a potential carcinogen, even at very low $\mu \mathrm{g}^{-1}$ level (WHO, 1991; USEPA, 1994). 
Considering the fact, the WHO favors a limit of $25 \mu \mathrm{g} \mathrm{l}^{-1}$ bromate in drinking water (WHO, 1995). The USEPA has established a drinking water maximum contamination level (MCL) of $10 \mu \mathrm{gl}^{-1}$ for bromate in finished drinking water (USEPA, 1994). Due to the potential adverse human health effects, the USEPA specified an MCL level of $60 \mu \mathrm{gl}^{-1}$ for the five specific HAAs in drinking water (USEPA, 1998). In the five HAAs, dichloroacetic acid and trichloroacetic acid are animal carcinogens (Richard and Hunter, 1996). Therefore, WHO has also set qualitative target levels for dichloroacetic acid $\left(50 \mu \mathrm{gl}^{-1}\right)$ and trichloroacetic acid (100 $\mu \mathrm{g}^{-1}$ ) in finished drinking water (WHO, 1995).

Generally, techniques such as ion chromatography (Weinberg, 1994; Jackson et al., 1998; Echigo et al., 2001), MS-based methods (Charles and Pepin, 1996; Magnuson, 1998; Creed and Brockhoff, 1999) could be used for the determination of bromate in drinking water. HAAs in drinking water could be detected with gas chromatography (Munch et al., 1995), capillary electrophoresis (Martinez et al., 1999), ion chromatography (Nair et al., 1994; Lopez-Avila et al., 1999) and MSbased techniques (Ells et al., 1999; Roehl et al., 2002).

Since there is no international MCLs on the DBPs in finished bottled drinking water, WHO advocates that persons seeking information on bottled drinking water certification should approach the national authorities in the country concerned. In China, there is no official legislation on the MCLs of DBPs in drinking water, and few data on the research of this area were reported $(\mathrm{Li}$ et al., 2001; Liu et al., 2002). In this paper, according the regulation of DBPs in drinking water of WHO, bromate and three chloroacetic acids in bottled drinking water samples commercially available in Beijing were investigated. For the low cost and simultaneous detection of the two kinds of compounds (bromate and chlorinated haloacetic acids) in one injection, ion chromatography was selected for the analysis. In this investigation, 10 typical brands of bottled drinking water samples were surveyed. For health concern, some anions and organic acids of interest were also detected.

\section{Material and methods}

\subsection{Chemicals}

All reagents used were of analytical reagent grade unless specified. Monochloroacetic acid (MCAA), dichloroacetic acid (DCAA), trichloroacetic acid (TCAA), bromate and chlorate were all bought from ChemService (USA). All solutions were prepared with deionized water further purified by EASYpure LF system (Barnstead, USA) with a specific resistance of $18.3 \mathrm{M} \Omega \mathrm{cm}$, filtered through a $0.2 \mu \mathrm{m}$ membrane filter. Fluoride, chloride, nitrite, bromide, nitrate, phosphate, sulfate, iodide, formic acid, acetic acid, oxalic acid, bromate, chlorate, MCAA and TCAA stock solutions (1000 $\mathrm{mg}^{-1}$ ) were prepared by dissolving the corresponding mass of solid compounds in purified water. DCAA stock solution was prepared with $99 \%$ DCAA solution. The stock solutions were stored in refrigerator at $4{ }^{\circ} \mathrm{C}$ and they could be stable for at least two weeks. Standard solutions were prepared daily by serial dilution of the stock solution prior to use.

\subsection{Sample collection}

Ten typical brands of bottled drinking water samples consisting of purified water, mineral water, natural water and distilled water types (Table 1) were purchased from supermarket stores in Beijing and assessed for good quality. The samples were purchased and analyzed in April 2002. All the bottled drinking water samples were in plastic containers with plastic screw caps. The capacities of the bottled water samples ranged from 550 to $600 \mathrm{ml}$. All the samples were produced in a week before the analysis. All the samples were ozonized before being bottled. Table 1 presents the specific information about the 10 brands of bottled drinking water samples.

\subsection{Sample pretreatment}

After the collection of the samples, all the samples were stored in refrigerator at $4{ }^{\circ} \mathrm{C}$ and analyzed within $1-4 \mathrm{~h}$.

In bottled drinking water, the concentrations of bromate, chlorate and chloroacetic acids were very low. In order to accurately detect the concentration of the compounds, the sample should be concentrated prior to analysis. The microwave-based evaporative concentration technique has been proved a convenient and effective method for the pretreatment of some thermally stable inorganic compounds in drinking water (Liu et al., 2002). In this section, the boiling points of

Table 1

Specific information about the bottled water samples

\begin{tabular}{llll}
\hline $\begin{array}{l}\text { Brand } \\
\text { type }\end{array}$ & Type & Source water & $\begin{array}{l}\text { Days after } \\
\text { production }^{\mathrm{a}}\end{array}$ \\
\hline 1 & Purified water & Tap water & 6 \\
2 & Mineral water & Ground water & 6 \\
3 & Natural water & Lake water & 5 \\
4 & Purified water & Tap water & 2 \\
5 & Spring water & Spring water & 4 \\
6 & Purified water & Tap water & 5 \\
7 & Mineral water & Ground water & 4 \\
8 & Purified water & Tap water & 4 \\
9 & Distilled water & Tap water & 5 \\
10 & Spring water & Spring water & 6 \\
\hline
\end{tabular}

${ }^{a}$ Means the days between the date of production and analysis. 
MCAA, DCAA and TCAA are all above $100{ }^{\circ} \mathrm{C}$. Other compounds detected will not be decomposed in $100{ }^{\circ} \mathrm{C}$. Consequently, the microwave-based evaporative technique could also be applied in this study.

In this experiment, the containers used for sample pretreatment were $100 \mathrm{ml}$ of PTFE beakers. With the beaker, $20 \mathrm{ml}$ of drinking water sample could be concentrated to less than $2 \mathrm{ml}$ in $10 \mathrm{~min}$ with the microwave oven (Philips, Whirlpool, $600 \mathrm{~W}$, output frequency: 2450 $\mathrm{MHz}$, USA) operated under middle-high level. During the concentration process, there was little solution splashed from the beaker. The concentrated solution was transferred to a well-calibrated $2.0 \mathrm{ml}$ PTFE vial, filled to $2.0 \mathrm{ml}$ with deionized water by micropipette, and then analyzed with IC. The results indicated that all the analytes had good recoveries except DCAA and TCAA. Both of the recoveries were less than $35 \%$. It was because in heated acidic aqueous solution, DCAA and TCAA could be decomposed. The $\mathrm{pH}$ value of the mixed standard solution of the 16 compounds was about 4.5. Therefore, the recoveries of the two compounds were very poor. However, DCAA and TCAA could be converted to dichloroacetate and trichloroacetate by reaction with alkaline solution. Dichloroacetate and trichloroacetate were thermally stable compounds and would not be decomposed during the concentration process. From Fig. 1, it could be seen that the recoveries of DCAA and TCAA were hugely enhanced along with the increasing of the $\mathrm{pH}$ value of the sample solution, which was adjusted with $1.0 \mathrm{M}$ sodium hydroxide. When the $\mathrm{pH}$ value of the drinking water sample solution was adjusted to 10.5 , both the recoveries of DCAA and TCAA were more than $95 \%$.

Some research reported that MCAA might be hydrolyzed in alkali solution to form glycolate (Zhu, 1994), which would result in serious interference to the exact detection of MCAA. Additional experiment was done to study whether MCAA was hydrolyzed by adjusting its $20 \mathrm{mgl}^{-1}$ solution's $\mathrm{pH}$ value to 10.5 first, and then concentrated with the developed technique and

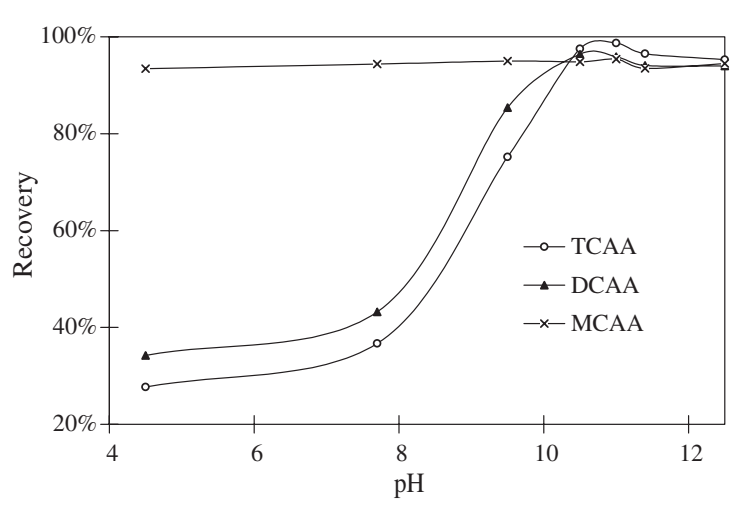

Fig. 1. Influence of the solution's $\mathrm{pH}$ on the recoveries of three chlorinated HAAs.

analyzed by IC. The final results indicated that no glycolate was found in the concentrated solution. It could be concluded that the microwave-based concentrating technique was available for all the 16 compounds with high recoveries by adjusting sample's $\mathrm{pH}$ value (Table 2).

\subsection{Sample analysis}

The analysis of the 16 analytes was accomplished with IC system (Dionex, DX500 series, USA) which consisted of an IonPac AG9HC guard column (Dionex, $4 \times 50 \mathrm{~mm}$, USA), an IonPac AS9HC separation column (Dionex, $4 \times 250 \mathrm{~mm}$, USA) for sample separation, an anion electrolytic suppressor (Dionex, Atlas, $4 \mathrm{~mm}$, USA) in autosuppression recycle mode, SC 20 suppressor controller for the control of the suppressor, a electrochemical detector (Dionex, ED 40, USA) in conductivity mode, a $500 \mu \mathrm{l}$ sample loop. Both instrumental control and data collection were performed with a personal computer and PeakNet 5.11 chromatography workstation (Dionex, USA). All tubing in the chromatography path (from the outlet of the pump to the exit of

Table 2

Recoveries of the analytes concentrated 10 -fold with microwave-based evaporative technique

\begin{tabular}{|c|c|c|c|c|c|c|c|c|}
\hline Analyte & $\mathrm{F}^{-}$ & $\mathrm{CH}_{3} \mathrm{COOH}$ & $\mathrm{HCOOH}$ & MCAA & $\mathrm{BrO}_{3}^{-}$ & $\mathrm{Cl}^{-}$ & $\mathrm{NO}_{2}^{-}$ & DCAA \\
\hline Concentration $\left(\mu \mathrm{g}^{-1}\right)$ & 5 & 20 & 10 & 10 & 10 & 5 & 10 & 10 \\
\hline $\begin{array}{l}\text { Found in the } 10 \text {-fold } \\
\text { concentrated solution }\end{array}$ & 54 & 188 & 95 & 93 & 94 & 52 & 91 & 92 \\
\hline Average recovery $(\%, n=7)$ & 107 & 94 & 95 & 93 & 94 & 104 & 91 & 92 \\
\hline \multirow[t]{2}{*}{$\operatorname{RSD}(\%, n=7)$} & 4.21 & 6.98 & 5.47 & 4.26 & 4.88 & 3.09 & 4.58 & 4.96 \\
\hline & $\mathrm{Br}^{-}$ & $\mathrm{ClO}_{3}^{-}$ & $\mathrm{NO}_{3}^{-}$ & $\mathrm{PO}_{4}^{3-}$ & $\mathrm{SO}_{4}^{2-}$ & $\mathrm{COOHCOOH}$ & TCAA & $\mathrm{I}^{-}$ \\
\hline Concentration $\left(\mu \mathrm{g}^{-1}\right)$ & 10 & 10 & 10 & 10 & 5 & 15 & 15 & 15 \\
\hline $\begin{array}{l}\text { Found in the } 10 \text {-fold } \\
\text { concentrated solution }\end{array}$ & 103 & 96 & 106 & 103 & 46 & 136 & 137 & 136 \\
\hline Average recovery $(\%, n=7)$ & 103 & 96 & 106 & 103 & 91 & 90 & 91 & 91 \\
\hline $\operatorname{RSD}(\%, n=7)$ & 5.51 & 4.22 & 4.37 & 5.69 & 4.11 & 5.45 & 4.56 & 6.86 \\
\hline
\end{tabular}


Table 3

Detection limits and linear ranges of analytes in original bottled water

\begin{tabular}{|c|c|c|c|c|c|c|c|c|}
\hline Analyte & $\mathrm{F}^{-}$ & $\mathrm{CH}_{3} \mathrm{COOH}$ & $\mathrm{HCOOH}$ & MCAA & $\mathrm{BrO}_{3}^{-}$ & $\mathrm{Cl}^{-}$ & $\mathrm{NO}_{2}^{-}$ & DCAA \\
\hline Concentration $\left(\mu \mathrm{gl}^{-1}\right)$ & 10 & 90 & 80 & 80 & 50 & 10 & 40 & 80 \\
\hline $\operatorname{RSD}(n=7, \%)$ & 2.88 & 2.67 & 2.08 & 2.71 & 3.01 & 1.45 & 1.39 & 1.09 \\
\hline Detection limit ${ }^{\mathrm{a}}\left(\mu \mathrm{g}^{-1}\right)$ & 0.009 & 0.18 & 0.03 & 0.06 & 0.06 & 0.01 & 0.04 & 0.14 \\
\hline $\begin{array}{l}\text { Concentration range } \\
\left(\mu \mathrm{gl}^{-1}\right)\end{array}$ & $0.01-60$ & $0.2-100$ & $0.1-100$ & $0.1-100$ & $0.06-100$ & $0.05-200$ & $0.5-100$ & $0.5-100$ \\
\hline \multirow{2}{*}{$\begin{array}{l}\text { Correlation } \\
\quad \text { coefficient }\left(r^{2}\right)\end{array}$} & 0.9912 & 0.9854 & 0.9934 & 0.9942 & 0.9901 & 0.9984 & 0.9981 & 0.9990 \\
\hline & $\mathrm{Br}^{-}$ & $\mathrm{ClO}_{3}^{-}$ & $\mathrm{NO}_{3}^{-}$ & $\mathrm{PO}_{4}^{3-}$ & $\mathrm{SO}_{4}^{2-}$ & $\mathrm{COOHCOOH}$ & TCAA & $\mathrm{I}^{-}$ \\
\hline Concentration $\left(\mu \mathrm{g}^{-1}\right)$ & 40 & 50 & 50 & 80 & 60 & 90 & 50 & 50 \\
\hline $\operatorname{RSD}(n=7, \%)$ & 1.82 & 1.66 & 1.59 & 1.43 & 1.75 & 1.46 & 1.83 & 1.49 \\
\hline Detection limit $^{\mathrm{a}}\left(\mu \mathrm{gl}^{-1}\right)$ & 0.07 & 0.08 & 0.06 & 0.22 & 0.11 & 0.15 & 0.85 & 0.32 \\
\hline $\begin{array}{l}\text { Concentration range } \\
\left(\mu \mathrm{gl}^{-1}\right)\end{array}$ & $0.5-100$ & $0.2-80$ & $0.5-4000$ & $0.5-500$ & 5-7000 & $1-800$ & $2-100$ & $1-100$ \\
\hline $\begin{array}{l}\text { Correlation } \\
\text { coefficient }\left(r^{2}\right)\end{array}$ & 0.9991 & 0.9990 & 0.9991 & 0.9989 & 0.9984 & 0.9914 & 0.9967 & 0.9937 \\
\hline
\end{tabular}

${ }^{\mathrm{a}}$ Calculated as three times of noise.

the cell) was PEEK $[0.005$ in $(0.125 \mathrm{~mm})$ ID]. The elution of sample was achieved with $11.5 \mathrm{mM} \mathrm{Na}_{2} \mathrm{CO}_{3}$ with which all the compounds could be well separated and detected. The current of the suppressor was set at $85 \mathrm{~mA}$. The flow rate of the eluent was kept at 1.0 $\mathrm{ml} \mathrm{min}{ }^{-1}$. The determination was performed at room temperature. All samples were injected in triplicate.

The following 16 compounds were determined: fluoride, chloride, nitrite, bromide, nitrate, phosphate, sulfate, iodide, formic acid, acetic acid, oxalic acid, bromate, chlorate, MCAA, DCAA, TCAA. The detection limits of the analytes were listed in Table 3.

\subsection{Quality control}

A strict regime of quality control was operated in the experiment. A bottled drinking water sample was spiked with working standard solution, preconcentrated and determined with ion chromatography. The results indicated that the average spiked recoveries $(n=7)$ of the compounds were ranged from $90 \%$ to $107 \%$, the relative standard deviation of the recoveries of each compounds were less than $3.5 \%$.

\section{Results and discussion}

\subsection{Results from the determination}

The concentrations of the DBPs and other compounds in the bottled drinking water samples were summarized in Table 4 . It could be seen that bromate could be found only in the water of Brand 3. DCAA and chlorate could be detected in the water of Brand 2, 3, 5, 7 and 10. Among the 10 brands of bottled drinking water samples, bromate, chlorate and DCAA had the highest concentrations in the spring water of Brand 3. It was $0.1,0.9$ and $0.6 \mu \mathrm{g}^{-1}$, respectively. Neither MCAA nor TCAA was detected in the purified water samples.

\subsection{Comparison of DBPs according to the different source waters}

As we know, the brand of bottled drinking water mainly comes from the characteristics of the source water. When the source water is from nature environment, such as lake, spring, etc., the ultimate products might be mineral water, spring water or natural water. When the source water is tap water, it will be processed to purified water.

In the 10 brands of bottled drinking water, the source waters could be summarized to four types, tap water, ground water, lake water and spring water. Because of the different original components and treatment technologies, the DBPs generated in the final drinking water samples differed much. From Fig. 2, it could be seen that DBPs could be produced during the ozonation when the source waters were ground water, spring water and lake water. This was because all the three waters were from nature environment, where naturally existed some organic compounds and inorganic ions such as bromide. During the production process, all the three water were only treated with simple procedures, such as filtration. The organic compounds and bromide might not be completely removed. When ozone was used for disinfection, the oxidant would react with the compounds to form some DBPs. In the three kinds of waters, because the lake water was from the deep layer of a lake, the concentrations of the organic compounds and bromide might be higher than those in the other water samples. The final concentrations of DBPs were a little higher, 

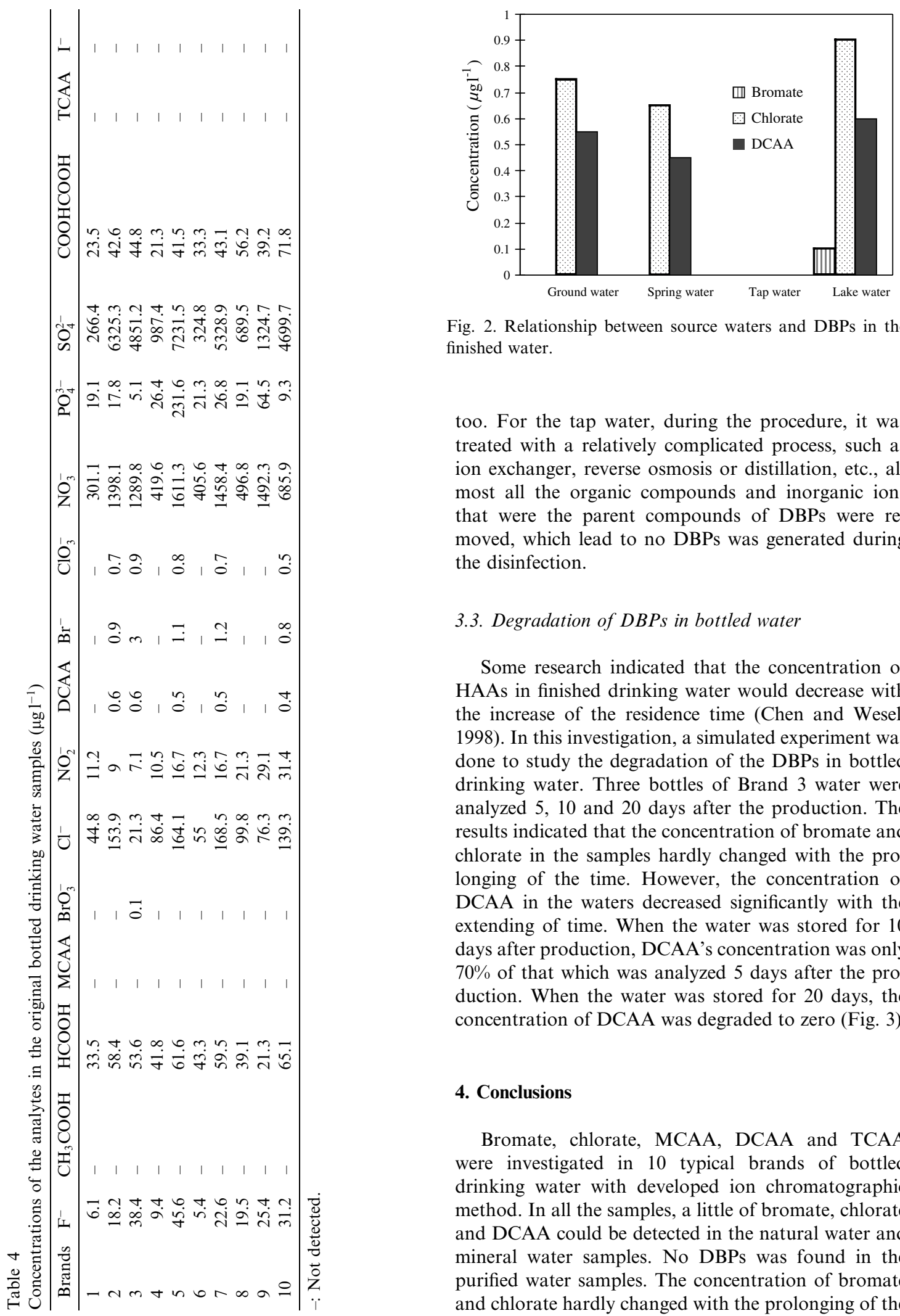

Fig. 2. Relationship between source waters and DBPs in the finished water.

too. For the tap water, during the procedure, it was treated with a relatively complicated process, such as ion exchanger, reverse osmosis or distillation, etc., almost all the organic compounds and inorganic ions that were the parent compounds of DBPs were removed, which lead to no DBPs was generated during the disinfection.

\subsection{Degradation of DBPs in bottled water}

Some research indicated that the concentration of HAAs in finished drinking water would decrease with the increase of the residence time (Chen and Wesel, 1998). In this investigation, a simulated experiment was done to study the degradation of the DBPs in bottled drinking water. Three bottles of Brand 3 water were analyzed 5, 10 and 20 days after the production. The results indicated that the concentration of bromate and chlorate in the samples hardly changed with the prolonging of the time. However, the concentration of DCAA in the waters decreased significantly with the extending of time. When the water was stored for 10 days after production, DCAA's concentration was only $70 \%$ of that which was analyzed 5 days after the production. When the water was stored for 20 days, the concentration of DCAA was degraded to zero (Fig. 3).

\section{Conclusions}

Bromate, chlorate, MCAA, DCAA and TCAA were investigated in 10 typical brands of bottled drinking water with developed ion chromatographic method. In all the samples, a little of bromate, chlorate and DCAA could be detected in the natural water and mineral water samples. No DBPs was found in the purified water samples. The concentration of bromate and chlorate hardly changed with the prolonging of the 


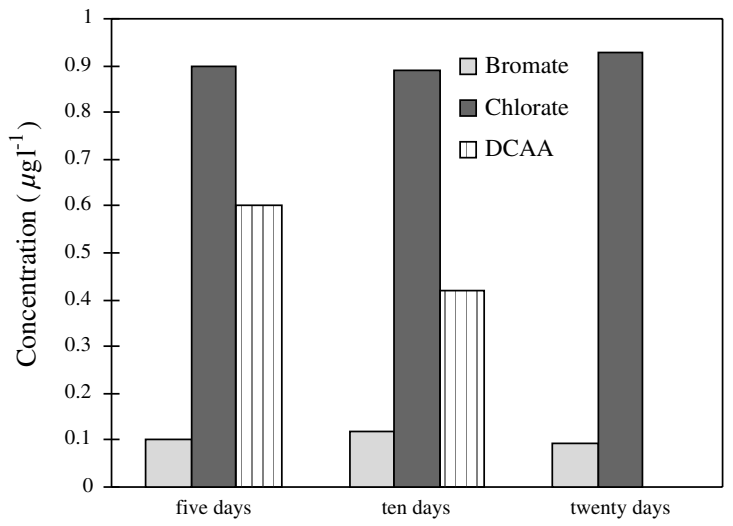

Fig. 3. Degradation of bromate, chlorate and DCAA in natural water.

storage time. DCAA would degrade much with increasing storage time.

\section{References}

Allen, L., Darby, J.L., 1994. Quality control of bottled and bended water in California: a review and comparison to tap water. J. Environ. Health 56, 17-22.

Calabrase, D.M., 1997. Bottled $\mathrm{H}_{2}$ O. Better Nutr. 59, 46.

Charles, L., Pepin, D., 1996. Electrospray ion chromatographytandem mass spectrometry of bromate at sub-ppb levels in water. Anal. Chem. 68, 2554-2558.

Chen, W.J., Wesel, C.P., 1998. Halogenated DBPs concentrations in a distribution system. J. Am. Water Works Assoc. 90, 151-163.

Creed, J.T., Brockhoff, C.A., 1999. Isotope dilution analysis of bromate in drinking water matrixes by ion chromatography with inductively coupled plasma mass spectrometric detection. Anal. Chem. 71, 722-726.

Dionex, 2000. Determination of inorganic oxyhalide disinfection byproduct anions and bromide in drinking water using ion chromatography with the addition of a postcolumn reagent for trace bromate analysis. Application Note 136, Dionex Corporation, Sunnyvale, CA, USA.

Dojlido, J., Zbiec, E., et al., 1999. Formation of the haloacetic acids during ozonation and chloration of water in Warsaw waterworks (Poland). Water Res. 33, 3111-3118.

Echigo, S., Minear, R.A., et al., 2001. Comparison of three post-column reaction methods for the analysis of bromate and nitrite in drinking water. J. Chromatogr. A 920, 205211.

Ells, B., Barnett, D.A., et al., 1999. Detection of chlorinated and brominated byproducts of drinking water disinfection using electrospray ionization-high-field asymmetric waveform ion mobility spectrometry-mass spectrometry. Anal. Chem. 71, 4747-4752.

Grguric, G., Trefry, J.H., et al., 1994. Ozonation products of bromine and chlorine in seawater aquaria. Water Res. 28, 1087-1094.
Ikem, A., Odueyungbo, S., et al., 2002. Chemical quality of bottled waters from three cities in eastern Alabama. Sci. Total Environ. 285, 165-175.

Jackson, L.K., Joyce, R.J., et al., 1998. Determination of trace level bromate in drinking water by direct injection ion chromatography. J. Chromatogr. A 829, 187-192.

Li, S., Zhang, X.J., et al., 2001. Formation and evolution of haloacetic acids in drinking water of Beijing city. J. Environ. Sci. Health A 36, 475-481.

Liu, Y.J., Mou, S.F., et al., 2002. Determination of trace level bromate and perchlorate in drinking water by ion chromatography with an evaporative preconcentration technique. J. Chromatogr. A 956, 85-92.

Lopez-Avila, V., Liu, Y., et al., 1999. Determination of haloacetic acids in water by ion chromatography-method development. J. AOAC Intern. 82, 689-704.

Magnuson, M.L., 1998. Determination of bromate at part-pertrillion levels by gas chromatography-mass spectrometry with negative chemical ionization. Anal. Chim. Acta 377, 53-60.

Martinez, D., Borrull, F., et al., 1999. Evaluation of different electrolyte systems and on-line preconcentrations for the analysis of haloacetic acids by capillary zone electrophoresis. J. Chromatogr. A 835, 187-196.

Misund, A., Frengstad, B., et al., 1999. Variation of 66 elements in European bottled mineral waters. Sci. Total Environ. 243/244, 21-41.

Munch, D.J., Munch, J.W., et al., 1995. EPA Method 552.2, Revision 1. Determination of haloacetic acids and dalapon in drinking water by liquid-liquid extraction, derivation and gas chromatography with electron capture detections, EPA/600/R/95/131, GPO: Washington, DC.

Nair, L.M., Saari-Nordhaus, R., et al., 1994. Determination of haloacetic acids by ion chromatography. J. Chromatogr. A 671, 309-313.

Pip, E., 2000. Survey of bottled drinking water available in Manitoba, Canada. Environ. Health Perspect. 108, 863-866.

Richard, A.M., Hunter, E.S., 1996. Quantitative structureactivity relationship for the developmental toxicity of haloacetic acids in mammalian whole embryo culture. Teratology 53, 352-360.

Roehl, R., Slingsby, R., et al., 2002. Application of ion chromatography with electrospray mass spectrometric detection to the determination of environmental contaminants in water. J. Chromatogr. A 956, 245-254.

USEPA, 1994. Disinfectants and disinfection byproducts: proposed rule. Fed. Reg., 38668-38829.

USEPA, 1998. Disinfectants and disinfection byproducts: final rule. Fed. Reg. 63, 69389-69476.

von Gunten, U., Oliveras, Y., 1998. Advanced oxidation of bromide-containing waters: bromate formation mechanisms. Environ. Sci. Technol. 32, 63-70.

Weinberg, H., 1994. Pre-concentration techniques for bromate analysis in ozonated waters. J. Chromatogr. A 671, 141149.

WHO, 1991. Revision of the WHO Guidelines for Drinking Water Quality, WHO, Geneva.

WHO, 1995. Desinfection del'eau, Local Authorities, Health and Environment Briefing Pamphlet Series, vol. 3.

Zhu, N.L., 1994. Handbook of Solvent, second ed. Chemical Industry Press, Beijing, p. 877. 